\title{
Editorial commentary on "Safety and Efficacy of Mirabegron: Analysis of a Large Integrated Clinical Trial Database of Patients with Overactive Bladder Receiving Mirabegron, Antimuscarinics, or Placebo"
}

\author{
Tomonori Yamanishi, Tomohiko Kamasasko, Kanya Kaga, Miki Fuse \\ Department of Urology, Continence Center, Dokkyo Medical University, Tochigi, Japan \\ Correspondence to: Tomonori Yamanishi, MD. Professor and Chairman, Department of Urology, Continence Center, Dokkyo Medical University, 880 \\ Kitakobayashi, Mibu, Tochigi, 321-0293, Japan. Email: yamanish@dokkyomed.ac.jp. \\ Provenance and Peer review: This article was commissioned by the editorial office, Translational Andrology and Urology. The article did not undergo \\ external peer review. \\ Comment on: Chapple CR, Cruz F, Cardozo L, et al. Safety and Efficacy of Mirabegron: Analysis of a Large Integrated Clinical Trial Database of \\ Patients with Overactive Bladder Receiving Mirabegron, Antimuscarinics, or Placebo. Eur Urol 2020;77:119-28.
}

Submitted Apr 02, 2020. Accepted for publication Apr 16, 2020.

doi: 10.21037/tau-2020-02

View this article at: http://dx.doi.org/10.21037/tau-2020-02

For the treatment of overactive bladder (OAB), physiotherapy and pharmaceutical therapies have been the main treatments of choice. The mainstays of medical therapy for $\mathrm{OAB}$ are antimuscarinics (AMs) and $\beta 3$ adorenoceptor (AR) agonists. Until recently, AMs were the most commonly used drugs and included oxybutynin (IR, ER and tape), propiverine, tolterodine, trospium, darifenacin, solifenacin and fesoterodine. There is considerable evidence from basic and clinical studies that shows the efficacy of these AMs. Clinical studies have demonstrated their efficacy in relieving symptoms based on various symptom scores, bladder diaries, and urodynamic studies. Basic studies include those that investigated muscarinic subtype selectivity, pharmacokinetics (such as half-life, tissue selectivity, transferability into central nervous system, etc.) (1). AMs have been reported to be effective not only for $\mathrm{OAB}$, but also neurogenic bladder resulting from spinal cord injury or spina bifida by decreasing detrusor overactivity or low compliance bladder (2). However, tolerability and adherence were low, probably due to side effects and/or lack of efficacy (3). The most common side effects of AMs are dry mouth, constipation, and blurred vision. Recently, AMs have been reported to affect the central nervous system and may cause cognitive dysfunction.
Recently, there have been reports that mirabegron (MIRA), a $\beta 3$-adorenoceptor (AR) agonist, may be an alternative to AMs in the treatment of OAB. MIRA has been reported to be more effective than placebo, have fewer side effects than AMs including dry mouth and constipation, and thus has better tolerability and adherence. It was also more cost-effective than AMs (4,5). A few other $\beta 3$-AR agonists have been developed for $\mathrm{OAB}$, but there is a lack of evidence for the efficacy and safety of these agents in the treatment of $\mathrm{OAB}(6)$.

We had the opportunity to read an interesting paper (Chapple et al.) recently published in the journal European Urology (4). This pooled data analysis of ten phase 2-4, double-blind, 12-week studies of MIRA monotherapy for OAB demonstrated that MIRA is effective, with improvements over placebo in the mean number of incontinence episodes/24 h, micturition/24 h, urgency episodes/24 h, volume voided/micturition, and nocturia episodes.

The authors assessed baseline $\mathrm{OAB}$-related characteristics, intrinsic and extrinsic factors, and analyses by age (<65 vs. $\geq 65 \mathrm{yr}$ and $<75 \mathrm{vs}$. $\geq 75 \mathrm{yr}$ ) and sex. Significant treatment-bysubgroup interactions from baseline in the mean number of incontinence episodes/24 h by age ( $<65 v s$. $\geq 65 \mathrm{yr}$ ), nocturia by age ( $<65 v s . \geq 65 \mathrm{yr}$ and $<75 v s . \geq 75 \mathrm{yr})$, and urgency 
episodes by previous medication were reported (4).

In this pooled data analysis, the characteristics of patient demographics were as follows: wet-OAB occurred in $44-51 \%$ of patients and was more prevalent in women; men represented $24-26 \%$ of subjects, and men had a higher number of nocturia episodes and number of micturition/24 h. Older age groups had a higher frequency of urgency incontinence and prior $\mathrm{OAB}$ medication use than younger age groups.

This paper also reviewed two studies on the combined use of solifenacin $(2.5-5 \mathrm{~g})+$ mirabegron $(25-50 \mathrm{mg})$ compared with solifenacin monotherapy $(5 \mathrm{mg})$, or mirabegron $(2.5-50 \mathrm{mg}$ ) or placebo (Symphony and Synergy trials). They concluded that the combination of solifenacin $(5 \mathrm{mg})+$ mirabegron $(25-50 \mathrm{mg})$ had greater efficacy and a slightly higher incidence of adverse events compared with monotherapy or placebo $(7,8)$.

However, there were no head-to-head comparisons of MIRA and AMs in the phase 2-4 studies because these AMs were used as active control drugs. The only study that compared tolterodine and MIRA was the phase II study reported by Chapple et al., and no between-drug differences were detected (9).

In the BEYOND study, a noninferiority, randomized trial was conducted to ascertain the efficacy and safety of MIRA compared to solifenacin in $\mathrm{OAB}$ patients who were dissatisfied with their previous AM treatment due to lack of efficacy. Non-inferiority was not demonstrated in the study (10). In the future, a head-to-head comparison of MIRA (or other $\beta 3$-AR agonists) and AMs might be necessary in naïve patients or those who were dissatisfied with their previous MIRA treatment.

However, there were significant differences between AMs and MIRA in terms of drug-related adverse events, i.e., $21.4 \%$ vs. $17 \%$, respectively; dry mouth was more frequent in the AM group (8.7\%) than in the MIRA group (2.7\%) and placebo group (2.4\%), and a similar, low frequency was reported among the groups for constipation (placebo $1.7 \%$, MIRA 2.1\%, and AM 2.4\%).

The frequencies of urinary retention were $\leq 1 \%$ in all treatment and age groups and both sexes, suggesting both AMs and MIRA rarely cause urinary retention. However, in these phase 2-4 studies, patients at risk of urinary retention, such as those having large postvoid residual urine volume (PVR), may be excluded, and men with benign prostatic hyperplasia may have been treated with $\alpha$-blockers. Therefore, increase in PVR should be carefully monitored in real-life practice.
The rise in TEAEs with age was greater in the AM population than in the MIRA population, and this was particularly striking for those aged $<75$ versus $\geq 75 \mathrm{yr}$, with increases in frequency of $2.1 \%$ (placebo), $2.9 \%$ (MIRA), and $9.4 \%(\mathrm{AM})$. The frequency of tachycardia was $\leq 1 \%$ in all treatment and age groups and for both sexes. Regarding cardiovascular AEs associated with MIRA, the frequency of hypertension was similar among the MIRA, AM and placebo groups $(4,11)$, but a dose-dependent increase in pulse rate, although not clinically meaningful, has been reported.

Therefore, the authors concluded that mirabegron may be a better option than AMs for those aged $\geq 75 \mathrm{yr}$ and also for elderly patients susceptible to constipation (4).

Other than these analyses, the phase 2-4 studies referred to in this paper have several limitations: all studies were designed, managed, analyzed, and funded by only one sponsor company. Although all of the studies were well designed, placebo-controlled, double-blind studies with a similar protocol, with large number of patients, these company-designed studies may contain bias. Patients with polyuria (total daily urine volume $>3,000 \mathrm{~mL}$ ), PVR $>100$ $300 \mathrm{~mL}$, uncontrolled hypertension (systolic blood pressure $\geq 180 \mathrm{mmHg}$, or diastolic blood pressure $\geq 110 \mathrm{mmHg}$ ), severe tachycardia (pulse rate $\geq 110 \mathrm{bpm}$ ), and other diseases such as stress urinary incontinence or neurogenic bladder were strictly excluded. Thus, the recruited patients may be dissimilar to those seen by general practitioners, and patients must sign an informed consent form. The duration of these studies was fixed at three months, and the treatments were stopped at the end of this time. Thus, the dropout rates were very low, and it remains unclear whether patients accurately reported their actual symptoms. Therefore, these conditions would tend to be different from those found in real-life practice.

In cases where patients had taken medication for $\mathrm{OAB}$ previously or had been taking other drugs, this could have affected the results.

The patients included in the study may have discontinued AMs prior to enrollment for various reasons including side effects or lack of efficacy. In patients with prior $\mathrm{OAB}$ treatment, $69.0 \%, 77.6 \%$, and $51.0 \%$ in the MIRA, AM, and placebo groups, respectively, had discontinued one or more prior treatments (mostly AMs) due to lack of efficacy. Thus, AMs may not have been effective from the time the study was initiated in these patients, but were naïve to MIRA.

The mechanism of action of $\beta 3$-AR agonists is reported 
to be the promotion of detrusor relaxation during urine storage, while that of $\mathrm{AM}$ is to inhibit detrusor contraction during voiding, and both drugs have been reported to inhibit the activity of afferent nerves. There are many reports on the urodynamic action of AMs to inhibit detrusor overactivity (DO), and thus have been reported to be effective not only for $\mathrm{OAB}$ but also in neurogenic DO. However, there are only a few reports on urodynamic studies of MIRA in patients with non-neurogenic DO or neurogenic DO. Therefore, the differences in how $\beta 3$-AR agonists and AMs inhibit detrusor contraction, including neurogenic DO, remain to be elucidated.

A high placebo response was observed, even though the effects of active drugs were greater than placebo. The reasons for the placebo effect may be that patients were monitored by keeping a bladder diary and voluntarily corrected their life styles including restricting fluid intake. Therefore, $160-500$ patients in each treatment arm were required to demonstrate statistically significant improvements in patients treated with active drugs compared to placebo.

Finally, in the future, a long-term, head-to head comparison between $\beta 3-\mathrm{AR}$ agonists and AMs is necessary to elucidate the role of these drugs.

\section{Acknowledgments}

Funding: None.

\section{Footnote}

Conflicts of Interest: All authors have completed the ICMJE uniform disclosure form (available at http://dx.doi. org/10.21037/tau-2020-02). The authors have no conflicts of interest to declare.

Ethical Statement: The authors are accountable for all aspects of the work in ensuring that questions related to the accuracy or integrity of any part of the work are appropriately investigated and resolved.

Open Access Statement: This is an Open Access article distributed in accordance with the Creative Commons Attribution-NonCommercial-NoDerivs 4.0 International License (CC BY-NC-ND 4.0), which permits the noncommercial replication and distribution of the article with the strict proviso that no changes or edits are made and the original work is properly cited (including links to both the formal publication through the relevant DOI and the license). See: https://creativecommons.org/licenses/by-nc-nd/4.0/.

\section{References}

1. Yamanishi T, Chapple CR, Chess-Williams R. Which muscarinic receptor is important in the bladder? World J Urol 2001;19:299-306.

2. Watanabe M, Yamanishi T, Honda M, et al. Efficacy of tolterodine ER for the treatment of neurogenic detrusor overactivity and/or low compliance bladder. Int J Urol 2010;17:931-6.

3. Chapple CR, Nazir J, Hakimi Z, et al. Persistence and Adherence with Mirabegron versus Antimuscarinic Agents in Patients with Overactive Bladder: A Retrospective Observational Study in UK Clinical Practice. Eur Urol 2017;72:389-99.

4. Chapple CR, Cruz F, Cardozo L, et al. Safety and Efficacy of Mirabegron: Analysis of a Large Integrated Clinical Trial Database of Patients with Overactive Bladder Receiving Mirabegron, Antimuscarinics, or Placebo. Eur Urol 2020;77:119-28.

5. Yamanishi Y, Yamanishi T, Tajima H, et al. Mirabegron or tolterodine for the treatment of overactive bladder in Japan: Which drug is more cost-effective as the first-line treatment? Int J Urol 2018;25:863-70.

6. Yoshida M, Takeda M, Gotoh M, et al. Efficacy of novel $\beta 3$-adrenoreceptor agonist vibegron on nocturia in patients with overactive bladder: A post-hoc analysis of a randomized, double-blind, placebo-controlled phase 3 study. Int J Urol 2019;26:369-75.

7. Abrams P, Kelleher C, Staskin D, et al. Combination treatment with mirabegron and solifenacin in patients with overactive bladder: efficacy and safety results from a randomised, double-blind, dose-ranging, phase 2 study (Symphony). Eur Urol 2015;67:577-88.

8. Herschorn S, Chapple CR, Abrams P, et al. Efficacy and safety of combinations of mirabegron and solifenacin compared with monotherapy and placebo in patients with overactive bladder (SYNERGY study). BJU Int 2017;120:562-75.

9. Chapple CR, Dvorak V, Radziszewski P, et al. Dragon Investigator Group. A phase II dose-ranging study of mirabegron in patients with overactive bladder. Int Urogynecol J 2013;24:1447-58.

10. Batista JE, Kölbl H, Herschorn S, et al; BEYOND study 
group. The efficacy and safety of mirabegron compared with solifenacin in overactive bladder patients dissatisfied with previous antimuscarinic treatment due to lack of efficacy: results of a noninferiority, randomized, phase IIIb trial. Ther Adv Urol 2015;7:167-79.

Cite this article as: Yamanishi T, Kamasasko T, Kaga K, Fuse M. Editorial commentary on "Safety and Efficacy of Mirabegron: Analysis of a Large Integrated Clinical Trial Database of Patients with Overactive Bladder Receiving Mirabegron, Antimuscarinics, or Placebo". Transl Androl Urol 2020;9(3):1009-1012. doi:10.21037/tau-2020-02
11. Drake MJ, MacDiarmid S, Chapple CR, et al. Cardiovascular safety in refractory incontinent patients with overactive bladder receiving add-on mirabegron therapy to solifenacin (BESIDE). Int J Clin Pract 2017. doi: 10.1111/ijcp.12944. 